\begin{tabular}{|l|l|}
\hline Recibido / Received & 21 de noviembre de 2018 \\
\hline AcEPTAdo / AcEPTED & 10 de junio de 2020 \\
\hline PÁGinas / PAGES & De la 155 a la 157 \\
\hline
\end{tabular}

\title{
Diario de oración
}

\author{
Autor / Author \\ O'CONNOR, Flannery \\ Editorial / Publishing company \\ ENCUENTRO, Madrid 2018
}

DOI: https://doi.org/10.32466/eufv-rel.2020.7.527.155-157

La escritora sureña Flannery O’Connor escribió este diario entre enero de 1946 y septiembre de 1947. Se trata de una serie de cartas que dirige a Dios. Más que invitar a su lectura, nos atreveríamos sugerir que nos asomemos con respeto al alma desnuda de O'Connor y, descubramos, la intimidad de esta mujer con su creador.

No es un diario al uso, porque podríamos pensar que una chica de veinte años que decide escribir uno va a llenar sus páginas con flirteos amorosos, con confesiones secretas en las que va desvelando sus ilusiones ante las posibilidades de vivir en una nueva ciudad, sus impresiones universitarias, sus enfrentamientos con alguna amiga y poco más. Nada más alejado de la realidad. O’Connor se había trasladado de Savannah a lowa City para realizar un programa de escritura creativa y, después, continuar con un Master of Fine Arts, pero en estas páginas no refleja su progresión creativa en sus escritos, se dirige de manera profunda e intensa a Dios.

Hasta ahora, cuando hablábamos de Flannery O’Connor y su relación con Dios, lo hemos podido hacer por la lectura de sus obras publicadas: treinta y dos relatos, dos novelas (Wise Blood y The Violent Bear It Away), parte de sus ensayos y conferencias (Mystery and Manners) y por sus cartas (The Habit of Being). En nuestro caso, hemos podido conocerla más, leyendo algunas de sus cartas inéditas a las que tuvimos acceso gracias a la Universidad de Emory. Pero, ahora, todos nosotros tenemos el privilegio de podernos asomar algo más a esa relación a través de la lectura de Diario de oración.

Guadalupe Arbona e Isabel Berzal, encargadas de traducir el diario, nos comentan en la nota a la traducción española la pretensión de Flannery al escribir las cartas a Dios: «Algunos de sus colegas hablaban de la irracionalidad de la fe, y ella quería saber, desafiada por los que no creían, si increpaba a dios para estar tranquila» (p. 7). Propio de O'Connor, escucha a los que le rodean y hace suyas las preguntas de los otros; medita estos interrogantes y se los presenta a Dios; espera, escucha, reflexiona, se enfada, 
grita, calla y escribe todo. O'Connor comprende y le da forma a lo que aprende en sus escritos: relatos, novelas, cartas... El proceso no es fácil, duele el alma cuando pregunta y no entiende la respuesta. Este recorrido, que hasta la fecha intuíamos, lo constatamos ahora al leer las páginas que tenemos entre manos. Como Arbona y Berzal nos comentan, es Flannery O'Connor en esencia, relatando una experiencia vital que le acompaña siempre y que recoge en forma de diario en un momento de su vida: «La batalla que comienza en estas páginas se desarrollará a lo largo de toda su vida» (p. 7)

Podemos aproximarnos a Diario de oración de dos maneras. Lo más habitual es leer la nota a la traducción española y seguir con la lectura del diario. Ediciones Encuentro ha tenido el acierto de incluir el original manuscrito de Flannery. Nuestra recomendación es que, tras leer la nota introductoria, nos dirijamos al diario manuscrito. La experiencia es indescriptible. Todo es sagrado: una mujer que abre su corazón, su alma a Dios; habla con Él, le desafía porque necesita hacerlo para entender su mundo, su vida y acercarse más a su Señor. Un espíritu inquieto que sabe que nada tiene sentido si Dios no está ahí. Los lectores tenemos el privilegio de participar del encuentro entre esta mujer y su creador.

La lectura de estas páginas debe hacerse con un respeto infinito: «But what would I do about those feelings that are now fear, now joy, that lie too Deep to be touched by my understanding. I am afraid of insidious hands Oh Lord which grope into the darkness of my soul. Please be my guard against them. Please be the Cover at the top of the passage» (pp. 71-72). Resulta un tanto paradójico, Flannery, en unas de las primeras páginas de su diario se confiesa con Dios, cuenta que en ella hay pedantería y egocentrismo, que actúa de forma hipócrita y se avergüenza de lo que los otros pudieran pensar de ella si descubrieran esto. Probablemente la autora se esté refiriendo a situaciones de su vida en las que defiende su fe pero que, en el fondo de su ser, ella también se cuestiona. Nos aventuramos a este planteamiento porque podemos seguir leyendo: "Am I keeping my faith by lazyness, dear Lord? But that is an idea that would appeal to someone who could only think» (p. 72). Si embargo, al leer estas líneas, no podemos dejar de preguntarnos, si de alguna manera estamos entrando en un espacio sagrado. O'Connor con veinte años rogaba a Dios tener éxito como escritora, pero dudamos que en estos momentos pudiera estar pensando que su diario iba a ser leído por tantos de nosotros. Sea como fuere, al final, lo estamos haciendo, estamos entrando en su intimidad más absoluta, por ello debemos hacerlo casi de puntillas.

O'Connor, sin doblez, está presente en estas páginas que ahora abordamos. Contemplemos el trazo de cada letra, los tachones que acompañan sus renglones, las interrupciones de sus pensamientos, los cambios de ritmo... Todo ello refleja su alma y la relación intensa que mantiene con Dios. La autora se muestra unas veces agradecida, amorosa, entregada y sabiendo que solo siguiendo la voluntad de Él podrá alcanzar su plenitud: «Help me to ask you, oh Lord, for what is good for me to have, for what I can have and do your served by having" (p. 79). Otras veces, se pregunta por la autenticidad de su fe y si es un invento para sentirse fuerte ante las debilidades: «Dear God, I don't want to have invented my faith to satisfy my weakness, I don't want to have created God to my own image as they're so fond of saying. 
Please give me the needs any grace, oh Lord, and please don't let it be as hard to get as Kafka made it» (pp. 82-83). Vemos cómo en todo momento O'Connor le pide a Dios que la acompañe, la ilumine, la sostenga a lo largo del camino.

La obra con el título de A prayer journal fue publicada en Estados Unidos en el año 2013; hemos tenido que esperar cinco años para contar con la edición en castellano. Es un acontecimiento digno de celebrar que ya podamos disfrutar de esta edición que se ha acercado con tanta fidelidad a la obra de la autora. Gracias a este libro, los lectores de nuestro país podemos disfrutar de la más auténtica Flannery O'Connor.

\section{MIRÓ LÓPEZ, Susana}

Profesora doctora de Formación Humanística

Universidad Francisco de Vitoria (UFV)

Madrid (España) 